\title{
Study on the Difference between Volatile Constituents of the Different Parts from Elsholtzia ciliata by SHS-GC-MS
}

\author{
Xiaoming Wang ${ }^{1}$, Lili Gong2, Haiqiang Jiang2* \\ ${ }^{1}$ Institute of Medicinal Plant Development, Chinese Academy of Medical Sciences \& Peking Union Medical College, \\ Beijing, China \\ ${ }^{2}$ Department of Pharmacy, Shandong University of Traditional Chinese Medicine, Jinan, China \\ Email: *1mlwxm123@163.com
}

How to cite this paper: Wang, X.M., Gong, L.L. and Jiang, H.Q. (2017) Study on the Difference between Volatile Constituents of the Different Parts from Elsholtzia ciliata by SHS-GC-MS. American Journal of Analytical Chemistry, 8, 625-635. https://doi.org/10.4236/ajac.2017.810045

Received: August 15, 2017

Accepted: October 23, 2017

Published: October 26, 2017

Copyright (c) 2017 by authors and Scientific Research Publishing Inc. This work is licensed under the Creative Commons Attribution International License (CC BY 4.0).

http://creativecommons.org/licenses/by/4.0/

\begin{abstract}
In this study, the comparison of Elsholtzia ciliata volatile compounds from the stem (with leaf) and flower was acquired. The volatile compounds of these two parts from Elsholtzia ciliata aerial parts were respectively analyzed by a rapid and convenient static headspace injection technique coupled with gas chromatography-mass spectrometry and the relative contents of each constituent between the two different parts were determined by peak area normalization. 61 compounds were identified in the stem (with leaf) and flower, among which 39 components simultaneously exist. 47 and 53 compounds were separated and identified in the volatile compounds from the different parts of Elsholtzia ciliata, respectively. There were differences among some volatile constituents of the two parts, but the main constituents were all Elsholtzia ketone, caryophyllene, 3-octanol and Dehydroelsholtzia ketone. The most abundant components in the stem (with leaf) included Elsholtzia ketone (84.20\%), caryophyllene (4.3\%) and 3-octanol (3.11\%), while Elsholtzia ketone (88.03\%), caryophyllene $(3.33 \%)$ and 3 -octanol $(1.53 \%)$ were the main components in the flower. 8 single constituents were identified in the stem (with leaf) volatiles including 3-heptanone and linalool, while 14 constituents only including 2-methylbutanoic acid and Perillene have been found in the flower volatiles. Elsholtzia ketone was the main compound, and its concentration was significantly higher than other substances $(>80 \%$ of the total oils in $E I-$ sholtzia ciliata). The study provided an important scientific base for the further utilization of Elsholtzia ciliata resources and may be helpful for systematically understanding the constituents of volatile compounds of Elsholtzia ciliata.
\end{abstract}

\section{Keywords}

Elsholtzia ciliata, Volatile Constituents, Static Headspace Injection 
Technique, Gas Chromatography-Mass Spectrometry

\section{Introduction}

Elsholtzia ciliata (Thunb.) Hyland. (the Chinese name "Xiang Ru") is an annual herb that belongs to the Elsholtzia species that is widely distributed in China, Korea and Europe, and as a folk medicine in China for thousands of years.

There has been an increasing interest in Elsholtzia species because of its long history for the treatment of cold, fever, emesis, edema, diarrhea, edema, rheumatic arthritis, nephritis and so forth. Elsholtzia ciliata contains many bioactive constituents, including flavonoids, terpenes and essential oil components. Modern pharmacological studies have shown the effect of antibacterial, antiviral, analgesic, antifebrile, antioxidant, antispasmodic, diuretic, antitussive, expectorant and antiasthmatic activities. Their chemical compositions are diverse, including several classes of flavonoids, phenylpropanoids, terpenes and other compounds. Several studies on the chemical constituents of Elsholtzia ciliata have reported the presence of abundant volatile components [1] [2].

Elsholtzia ciliata, as a kind of aromatic plants with fragrant aroma, is rich in volatile component which is one of its main effective components. The oils of some Elsholtzia species show therapeutical efficacy against fever, cold, vomiting, heat stroke, edema and the enhancement of immunity [3] [4], which have a significant medicinal value in clinical application.

Different methods are available to analyze the essential oils in Elsholtzia ciliata including steam distillation and extraction with organic solvents. Conventional analytical techniques, such as solvent extraction and steam distillation, have been used to analyze the essential oils in Elsholtzia ciliata. Mostly, steam distillation requires a relatively large amount of sample, and it is time-consuming. Only a few extractions with carbon dioxide methods-supercritical fluid extraction (SFE) were also applied for this purpose [5] [6]. It has been widely adopted in headspace (HS) sampling which is a fundamental technique to characterize the volatile fraction of aromatic plants.

Due to the advantage of simple, rapid, low-cost and solvent-free, HS technique offers a more useful tool than the conventional analytical techniques [7]. However, there is little paper reported that HS was applied to analyze Elsholtzia ciliata. Depending on the applied method, the results of our experiments have shown that static headspace (HS) is a simple and fast technique because no sample preparation or solvent is needed. Therefore, the direct coupling with a mass spectrometer could carry out the detection of Elsholtzia ciliata oils. In this work, HS methods coupled with GC-MS were applied for extraction and identification of volatiles of the Elsholtzia ciliata stem (with leaf) and flower. The comparison of the volatiles of the Elsholtzia ciliata stem (with leaf) and flower was performed by using HS-GC-MS. 
Compared with the conventional methods, HS-GC-MS provides a simple preparation, small amounts of the sample, short times to extract the volatile constituents, and has no use for organic solvent. As the stem (with leaf) and flower volatiles of Elsholtzia ciliata were not yet investigated in detail, it is reported here the results obtained by HS-GC-MS analyses on the volatile compounds of the Elsholtzia ciliata stem (with leaf) and flower.

In this work, a direct, reliable and effective automated method has been built for the determination of the different portions of the plant based on headspace technique. Separation, identification and quantization were carried out by HS-GC-MS. Sample pretreatment or clean-up were not necessary, as samples are put directly into an HS vial, automatically processed and then injected to the GC-MS for chromatographic analysis.

The plant consisted of varies of tissues and organs. Generally, chemical compositions of the plant are probably a whole macro characteristic referring to all the plant parts. However, only a few researches on the comparison of different parts of the plant. The description of medicinal parts in the clinical application mostly used the whole plant or taken from a certain parts of the plant, such as only using roots, rhizomes, leaves, flowers or fruits-divided into the medicinal parts and non-medicinal parts [8]. The medicinal parts and non-medicinal parts have certain differences in medicinal properties and pharmacological effects. In addition, the harvesting time and location may also affect the differences, leading to the lack of unified standard for the selection of the medicinal parts. In practice, the correlation of different parts was always ignored and the non-medicinal part was often discarded as waste. To some extent, the different plant parts may act synergistically in ways we don't know. Full utilization of plant resources is an unsolved problem due to the lack of unified standard for the selection of medicinal parts.

The medicinal parts of Elsholtzia ciliata were the aerial parts in the Chinese Pharmacopoeia, flowering whole parts is recorded in the Traditional Chinese Medicine Dictionary, while the whole parts or aerial parts in the Chinese Materia Medica. Roots were picked-off in order to obtain the processed products. In ancient china, only the Elsholtzia ciliata leafs or the flowers and leafs were used together. Most experiments are carried out by using the Elsholtzia ciliata aerial parts. Researches on the pharmacological effect of the different parts from EIsholtzia ciliata have shown a certain difference [9]. In China, the Elsholtzia ciliata have been applied to the treatment of lots of diseases for a long time. However, up to date, the medicinal parts are still unclear. However, the volatile components of the different Elsholtzia ciliata parts were not investigated in detail. In our project, efforts were devoted to analysis and compare the difference of the volatiles of the different Elsholtzia ciliata parts by HS-GC-MS.

The whole plants contained $0.2 \%$ - $1 \%$ essential oils, the fresh stems and flowers contained $0.26 \%-0.59 \%$ essential oils and the dried stems and flowers contained $0.8 \%$ - $2 \%$ essential oils. Respectively, with the main chemical classes: El- 
sholtzione (85\%) and Acetophenone (1\%). In order to figure out whether the differences existed or not, this project aimed to quickly compare the volatiles of different parts of Elsholtzia ciliata with regards to the conventional direct HS-GC-MS method. In the proposed method, sampling with HS technique for GC analysis is a rapid and effective method for the analysis of volatiles in samples. Based on the chemical compounds, the project revealed the differences in chemical composition of different parts, explored the possibility of material basis of Traditional Chinese Medicine and the pharmacological effects, selected the medicinal parts, strengthened quality management and to standardize clinical application.

\section{Materials and Methods}

\subsection{Plant Materials}

The aerial parts of Elsholtzia ciliata were collected from Qixia Mountain, Shandong, China in the middle of September, 2012, and were authenticated by Associate Professor Sun Zhiying from the Department of Pharmacy, Shan Dong University of Traditional Chinese Medicine in China. The two parts of stem (with leaf) and flower samples were separated from the aerial parts in our laboratory, respectively. These two parts were stored in the dark at room temperature until use. The dried stems (with leafs) and flowers were respectively ground into powder (40 mesh) and kept at a desiccators prior to analysis.

\subsection{HS-GC/MS Analyses}

\subsubsection{Extraction of Volatile Components}

Dried stems (with leafs) and flowers powder $(0.5 \mathrm{~g})$ were precisely weighed into $10 \mathrm{~mL}$ HS vial and sealed hermetically with a PTFE-silicone septum and an aluminum cap and then carefully marked, respectively. An Agilent 7694 EAutomatic sampler (Agilent Technologies, USA) was used as a HS sampler. The HS sampling parameters were set as follows: Vial temperature, $120^{\circ} \mathrm{C}$; Loop temperature, $140^{\circ} \mathrm{C}$; Transfer-line temperature, $160^{\circ} \mathrm{C}$; Vial equilibration, $30 \mathrm{~min}$; Loop equilibration, $0.05 \mathrm{~min}$; sample injection, $1 \mathrm{~min}$.

\subsubsection{GC-MS Analyses}

The analysis of volatile compounds of the two parts obtained by HS was performed on an Agilent 6890-5975B GC-MS system (Agilent Technologies, USA). The chromatography conditions were as follows: HP-5MS (30 $\mathrm{m} \times 0.25 \mathrm{~mm}$ i.d. $\times$ $0.25 \mu \mathrm{m}$ film thickness); helium as the carrier gas, flow rate of $1.0 \mathrm{~mL} \cdot \mathrm{min}^{-1}$ and with split ratio of $3: 1$; the injector temperature was at $250^{\circ} \mathrm{C}$. The temperature programmed as follows: from $40^{\circ} \mathrm{C}(3$ minutes $)$ to $100^{\circ} \mathrm{C}$ at a rate of $2^{\circ} \mathrm{C} \cdot \mathrm{min}^{-1}$, from $100^{\circ} \mathrm{C}\left(2\right.$ minutes) to $150^{\circ} \mathrm{C}$ at a rate of $1^{\circ} \mathrm{C} \cdot \mathrm{min}^{-1}$, and then from $150^{\circ} \mathrm{C}(2$ minutes) to $280^{\circ} \mathrm{C}$ at a rate of $10^{\circ} \mathrm{C} \cdot \mathrm{min}^{-1}$, with a final hold of 5 minutes at $280^{\circ} \mathrm{C}$.

The mass spectrometer was fitted with EI source operated $70 \mathrm{eV}$, and mass spectra were recorded in the $\mathrm{m} / \mathrm{z}$ range of 50 to $550 \mathrm{~m} / \mathrm{z}$ with full-scan acquisi- 
tion mode. A "Standard Tune" option was used. The ion source of the mass spectrometer was set at $230^{\circ} \mathrm{C}$. Quadrupole temperature and transfer-line temperature were $150^{\circ} \mathrm{C}$ and $280^{\circ} \mathrm{C}$, respectively.

\section{Results and Discussions}

The analysis of the two different parts from Elsholtzia ciliata was performed on the above mentioned HS-GC-MS conditions; the total ionization chromatography of the volatiles of the two different parts was shown in Figure 1 and Figure 2. The separated volatile components were identified by the NIST MS library search (NIST MS Search 2.0) and comparison with literatures [10]-[19]. The relative contents of each constituent from the volatile constituents were determined by area normalization method. The identified compound with their relative amounts from Elsholtzia ciliata stem (with leaf) and flower was summarized in Table 1. The comparison of the major constituents between the two different

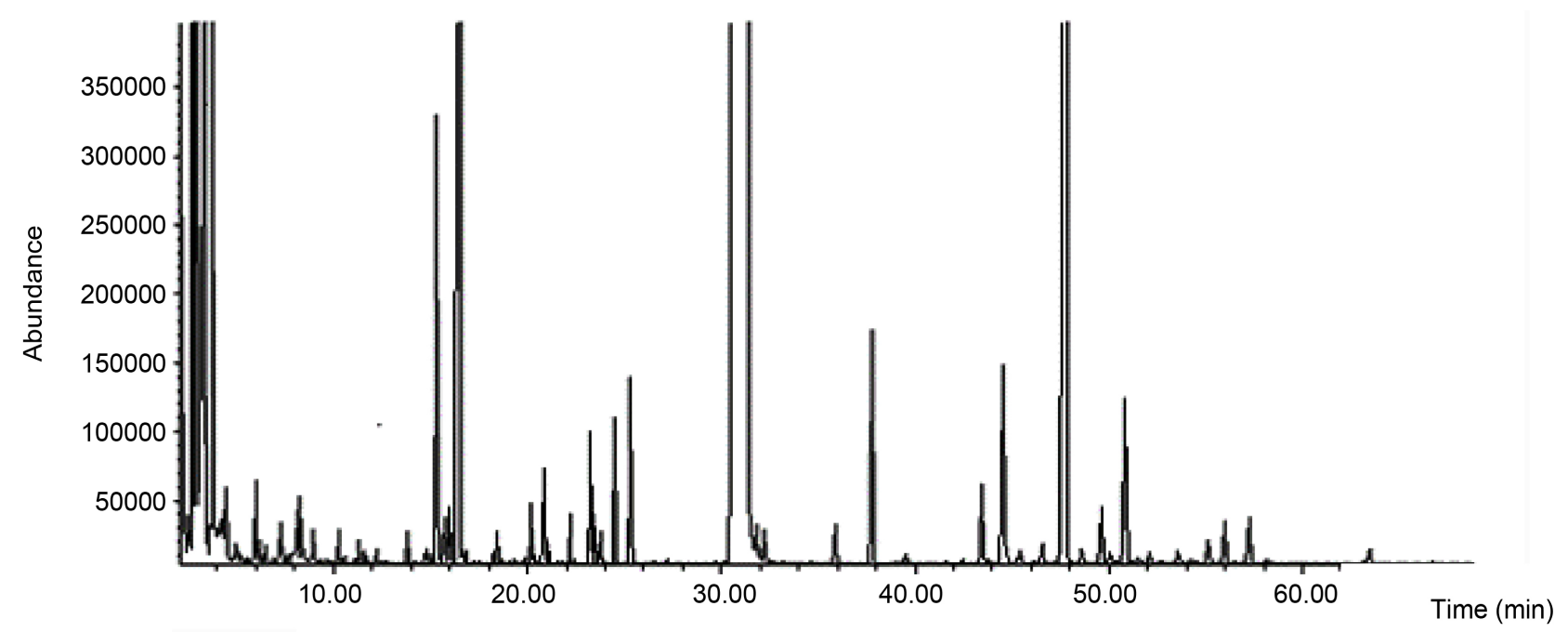

Figure 1. Total ionization chromatography of volatile compounds of Elsholtzia ciliata stem and leaf by HS-GC-MS.

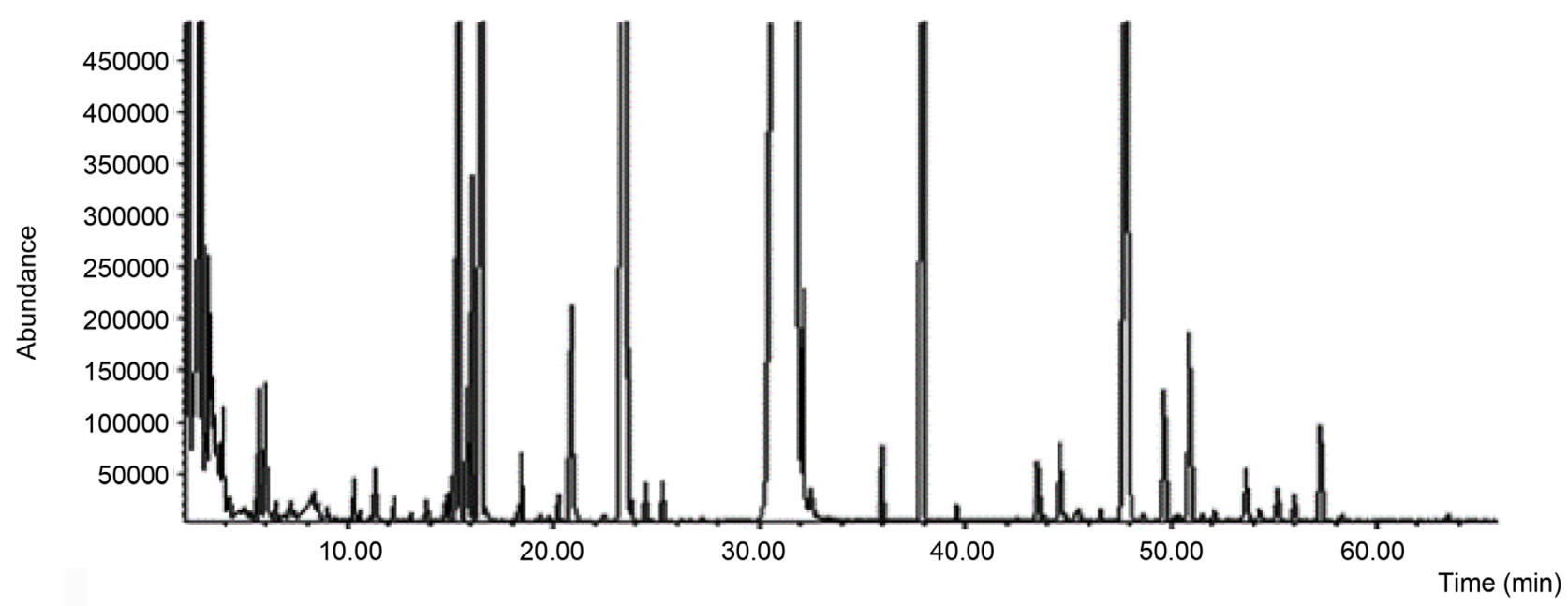

Figure 2. Total ionization chromatography of volatile compounds of Elsholtzia ciliata flower by HS-GC-MS. 
parts was listed in Table 2. In total, 61 compounds (more than 90\% of match scores) were identified in the two different parts. 47 compounds accounting for $96.07 \%$ of total volatiles were identified in the Elsholtzia ciliata stem (with leaf). 53 compounds constituting $97.94 \%$ of total volatiles were identified in the Elsholtzia ciliata flower (Table 1). 13 main compounds were found in both the two different parts, but each of them exhibited different relative contents (Table 2).

Seen from Table 1, a total of 61 compounds were identified in the two different parts, 47 compounds constituting $96.07 \%$ of the total volatiles were identified in stems (with leafs) with Elsholtzia ketone being the main constituent (84.20\%) and 53 compounds accounting for $97.94 \%$ of the total volatiles were identified in flowers with Elsholtzia ketone being the main component (88.03\%). 39 compounds were found both in the two different parts. 8 compounds were only detected in the stem and leaf, or shown extremely low content in the flower. In contrast, 14 compounds were only detected in the flower, or were little contained in the stem and leaf. The differential peak accounted for a very small but significant proportion, indicating that the types of the volatile components contained in the stem and leaf were different to some extent with those contained in the flower of Elsholtzia ciliata. The difference can serve as a basis to quickly analysis the volatile components contained in different parts of Elsholtzia ciliata.

Several literatures reported the volatile components of this plant [13]-[19] used different techniques of extractions including HD, SFE and HS-SPME, they showed significant differences in the composition of the volatile constituents. Saini R et al. [19] firstly made a comparative evaluation of the constituents using those three different extraction procedures, the proposed HS method is simple, fast and inexpensive without complicated sample pre-treatment. $\gamma$-Terpinene, Perillene, 1-Octen-3-yl-acetate, Linalool, Geranyl acetate, Caryophyllene, Humulene, Germacrene D were found as common constituents of these three extractions.3-Octen-1-ol, Cubebeneand Cadinene were only found in SFE and HD samples. In our study, the compositions of the volatile components were mainly ketones, terpenes, alcohols, aldehydes and phenols, etc. (Figure 3). Other key marker volatile constituents of different species such as Elsholtzia ketone, Dehydroelsholtzia ketone and Thymol were also reported in the Elsholtzia ciliata. Linalool, Geranyl acetate have earlier been reported as one of the major constituents of E. blanda, but was absent from all the other species. It was identified in low percentage in the present investigation. Perillene is one of the key marker volatile constituents of $E$. fruiticosa oil, but was identified in low percentage in the Elsholtzia ciliata flower.

Some alcohols and ketones with a lower boiling point and earlier RT were only detected in the stem and leaf such as Linalool; some terpenes with a higher boiling point and later RT were only detected in the flower, among which a major active component, Perillene, showed a content of $0.22 \%$. The different composition was manifested as alcohols and ketones mainly in the stem and leaf and terpenes mainly in the flower. The main constituents of the volatile components 
Table 1. HS-GC-MS analytical results of volatile compounds from the two different parts of Elsholtzia ciliata.

\begin{tabular}{|c|c|c|c|c|c|}
\hline \multirow[b]{2}{*}{ No } & \multirow[b]{2}{*}{$\mathrm{RT} / \mathrm{min}$} & \multirow[b]{2}{*}{ Compound } & \multirow[b]{2}{*}{ Formula } & \multicolumn{2}{|c|}{ Relative Content/\% } \\
\hline & & & & $\begin{array}{c}\text { stem } \\
\text { (with leaf) }\end{array}$ & flower \\
\hline 1 & 5.51 & 3-Hexanone & $\mathrm{C}_{6} \mathrm{H}_{12} \mathrm{O}$ & - - & $0.01 \%$ \\
\hline 2 & 5.67 & $(\mathrm{R}, \mathrm{R})$-2,3-Butanediol & $\mathrm{C}_{4} \mathrm{H}_{10} \mathrm{O}_{2}$ & - & $0.06 \%$ \\
\hline 3 & 5.99 & Hexanal & $\mathrm{C}_{6} \mathrm{H}_{12} \mathrm{O}$ & $0.09 \%$ & $0.09 \%$ \\
\hline 4 & 6.15 & 2,3-Butanediol & $\mathrm{C}_{4} \mathrm{H}_{10} \mathrm{O}_{2}$ & $0.03 \%$ & -- \\
\hline 5 & 7.24 & Furfural & $\mathrm{C}_{5} \mathrm{H}_{4} \mathrm{O}_{2}$ & $0.06 \%$ & $0.03 \%$ \\
\hline 6 & 7.37 & 3-Heptanone & $\mathrm{C}_{7} \mathrm{H}_{14} \mathrm{O}$ & $0.03 \%$ & -- \\
\hline 7 & 8.13 & 3-Methylpentanoic acid & $\mathrm{C}_{6} \mathrm{H}_{12} \mathrm{O}_{2}$ & $0.11 \%$ & $0.06 \%$ \\
\hline 8 & 8.31 & 3-Hexen-1-ol & $\mathrm{C}_{6} \mathrm{H}_{12} \mathrm{O}$ & $0.11 \%$ & $0.04 \%$ \\
\hline 9 & 8.56 & 2-Methylbutanoic acid & $\mathrm{C}_{5} \mathrm{H}_{10} \mathrm{O}_{2}$ & -- & $0.03 \%$ \\
\hline 10 & 8.81 & p-Xylene & $\mathrm{C}_{8} \mathrm{H}_{10}$ & $0.01 \%$ & -- \\
\hline 11 & 8.97 & 1-Hexanol & $\mathrm{C}_{6} \mathrm{H}_{14} \mathrm{O}$ & $0.04 \%$ & $0.01 \%$ \\
\hline 12 & 10.28 & 2,5-Diethyltetrahydrofuran & $\mathrm{C}_{8} \mathrm{H}_{16} \mathrm{O}$ & $0.04 \%$ & $0.03 \%$ \\
\hline 13 & 10.59 & Heptanal & $\mathrm{C}_{7} \mathrm{H}_{14} \mathrm{O}$ & -- & $0.01 \%$ \\
\hline 14 & 11.34 & $\beta$-Pinene & $\mathrm{C}_{10} \mathrm{H}_{16}$ & $0.02 \%$ & $0.05 \%$ \\
\hline 15 & 12.23 & $\alpha$-Pinene & $\mathrm{C}_{10} \mathrm{H}_{16}$ & $0.02 \%$ & $0.02 \%$ \\
\hline 16 & 13.05 & Camphene & $\mathrm{C}_{10} \mathrm{H}_{16}$ & -- & $0.01 \%$ \\
\hline 17 & 13.84 & Benzaldehyde & $\mathrm{C}_{7} \mathrm{H}_{6} \mathrm{O}$ & $0.04 \%$ & $0.02 \%$ \\
\hline 18 & 14.78 & $\alpha$-Thujene & $\mathrm{C}_{10} \mathrm{H}_{16}$ & $0.03 \%$ & $0.02 \%$ \\
\hline 19 & 15.01 & 2-Acetyl-5-methylfuran & $\mathrm{C}_{7} \mathrm{H}_{8} \mathrm{O}_{2}$ & -- & $0.04 \%$ \\
\hline 20 & 15.38 & 3-Octen-1-ol & $\mathrm{C}_{8} \mathrm{H}_{16} \mathrm{O}$ & $0.61 \%$ & $0.69 \%$ \\
\hline 21 & 15.78 & 3-Octanone & $\mathrm{C}_{8} \mathrm{H}_{16} \mathrm{O}$ & $0.08 \%$ & $0.12 \%$ \\
\hline 22 & 16.03 & $\beta$-Myrcene & $\mathrm{C}_{10} \mathrm{H}_{16}$ & $0.07 \%$ & $0.24 \%$ \\
\hline 23 & 16.47 & 3-Octanol & $\mathrm{C}_{8} \mathrm{H}_{18} \mathrm{O}$ & $3.11 \%$ & $1.53 \%$ \\
\hline 24 & 16.68 & Neodihydrocarveol & $\mathrm{C}_{10} \mathrm{H}_{18} \mathrm{O}$ & $0.02 \%$ & $0.01 \%$ \\
\hline 25 & 16.82 & Octanal & $\mathrm{C}_{8} \mathrm{H}_{16} \mathrm{O}$ & $0.02 \%$ & -- \\
\hline 26 & 17.51 & Isoterpinolene & $\mathrm{C}_{10} \mathrm{H}_{16}$ & -- & $0.01 \%$ \\
\hline 27 & 18.31 & D-Limonene & $\mathrm{C}_{10} \mathrm{H}_{18} \mathrm{O}$ & $0.01 \%$ & $0.01 \%$ \\
\hline 28 & 18.45 & Eucalyptol & $\mathrm{C}_{10} \mathrm{H}_{18} \mathrm{O}$ & $0.04 \%$ & $0.05 \%$ \\
\hline 29 & 20.23 & Menthone & $\mathrm{C}_{10} \mathrm{H}_{18} \mathrm{O}$ & $0.08 \%$ & $0.02 \%$ \\
\hline 30 & 20.44 & $\gamma$-Terpinene & $\mathrm{C}_{10} \mathrm{H}_{16}$ & $0.01 \%$ & -- \\
\hline 31 & 20.85 & Acetophenone & $\mathrm{C}_{8} \mathrm{H}_{8} \mathrm{O}$ & $0.15 \%$ & $0.26 \%$ \\
\hline 32 & 23.28 & Thymol & $\mathrm{C}_{10} \mathrm{H}_{14} \mathrm{O}$ & $0.17 \%$ & $0.58 \%$ \\
\hline 33 & 23.50 & Linalool & $\mathrm{C}_{10} \mathrm{H}_{18} \mathrm{O}$ & $0.08 \%$ & -- \\
\hline 34 & 23.60 & Perillene & $\mathrm{C}_{10} \mathrm{H}_{14} \mathrm{O}$ & -- & $0.22 \%$ \\
\hline 35 & 23.80 & Nonanal & $\mathrm{C} 9 \mathrm{H}_{18} \mathrm{O}$ & $0.04 \%$ & $0.02 \%$ \\
\hline 36 & 24.51 & Octen-1-ol, acetate & $\mathrm{C}_{10} \mathrm{H}_{18} \mathrm{O}_{2}$ & $0.19 \%$ & $0.03 \%$ \\
\hline 37 & 25.33 & 3-Octanol, acetate & $\mathrm{C}_{10} \mathrm{H}_{20} \mathrm{O}_{2}$ & $0.25 \%$ & $0.03 \%$ \\
\hline 38 & 26.19 & Camphor & $\mathrm{C}_{10} \mathrm{H}_{16} \mathrm{O}$ & -- & $0.01 \%$ \\
\hline 39 & 31.37 & Elsholtzia ketone & $\mathrm{C}_{10} \mathrm{H}_{14} \mathrm{O}_{2}$ & $84.20 \%$ & $88.03 \%$ \\
\hline
\end{tabular}




\section{Continued}

\begin{tabular}{|c|c|c|c|c|c|}
\hline 40 & 35.96 & Eucarvone & $\mathrm{C}_{10} \mathrm{H}_{14} \mathrm{O}$ & $0.06 \%$ & $0.07 \%$ \\
\hline 41 & 37.80 & Jasmone & $\mathrm{C}_{11} \mathrm{H}_{16} \mathrm{O}$ & - - & $0.01 \%$ \\
\hline 42 & 37.97 & Dehydroelsholtzia ketone & $\mathrm{C}_{10} \mathrm{H}_{12} \mathrm{O}_{2}$ & $0.41 \%$ & $1.23 \%$ \\
\hline 43 & 38.70 & Thymol acetate & $\mathrm{C}_{12} \mathrm{H}_{16} \mathrm{O}_{2}$ & -- & $0.01 \%$ \\
\hline 44 & 43.48 & Geranyl acetate & $\mathrm{C}_{12} \mathrm{H}_{20} \mathrm{O}_{2}$ & $0.15 \%$ & $0.06 \%$ \\
\hline 45 & 44.57 & $\beta$-Bourbonene & $\mathrm{C}_{15} \mathrm{H}_{24}$ & $0.45 \%$ & $0.08 \%$ \\
\hline 46 & 44.85 & Artemesiatriene & $\mathrm{C}_{10} \mathrm{H}_{16}$ & -- & $0.01 \%$ \\
\hline 47 & 45.46 & $\pi$-Gurjunene & $\mathrm{C}_{15} \mathrm{H}_{24}$ & $0.04 \%$ & $0.02 \%$ \\
\hline 48 & 46.60 & Isocaryophillene & $\mathrm{C}_{15} \mathrm{H}_{24}$ & $0.04 \%$ & $0.02 \%$ \\
\hline 49 & 47.82 & Caryophyllene & $\mathrm{C}_{15} \mathrm{H}_{24}$ & $4.3 \%$ & $3.33 \%$ \\
\hline 50 & 48.60 & $\pi$-Cubebene & $\mathrm{C}_{15} \mathrm{H}_{24}$ & $0.03 \%$ & -- \\
\hline 51 & 49.63 & $\alpha$-Bergamotene & $\mathrm{C}_{15} \mathrm{H}_{24}$ & $0.12 \%$ & $0.17 \%$ \\
\hline 52 & 50.06 & $\pi$-Muurolene & $\mathrm{C}_{15} \mathrm{H}_{24}$ & $0.02 \%$ & -- \\
\hline 53 & 50.88 & Humulene & $\mathrm{C}_{15} \mathrm{H}_{24}$ & $0.37 \%$ & $0.24 \%$ \\
\hline 54 & 52.10 & $\pi$-Sesquiphellandrene & $\mathrm{C}_{15} \mathrm{H}_{24}$ & $0.02 \%$ & $0.01 \%$ \\
\hline 55 & 53.62 & Germacrene D & $\mathrm{C}_{15} \mathrm{H}_{24}$ & $0.03 \%$ & $0.07 \%$ \\
\hline 56 & 54.29 & $\pi$-Bisabolene & $\mathrm{C}_{15} \mathrm{H}_{24}$ & -- & $0.01 \%$ \\
\hline 57 & 55.16 & $\gamma$-Elemene & $\mathrm{C}_{15} \mathrm{H}_{24}$ & $0.05 \%$ & $0.04 \%$ \\
\hline 58 & 55.99 & $(\mathrm{Z}, \mathrm{E})$ - $\alpha$-Farnesene & $\mathrm{C}_{15} \mathrm{H}_{24}$ & $0.09 \%$ & $0.03 \%$ \\
\hline 59 & 57.26 & Nerolidol & $\mathrm{C}_{15} \mathrm{H}_{26} \mathrm{O}$ & $0.1 \%$ & $0.12 \%$ \\
\hline 60 & 58.13 & $\pi$-Cadinene & $\mathrm{C}_{15} \mathrm{H}_{24}$ & -- & $0.01 \%$ \\
\hline 61 & 63.46 & Caryophyllene oxide & $\mathrm{C}_{15} \mathrm{H}_{24} \mathrm{O}$ & $0.03 \%$ & $0.01 \%$ \\
\hline
\end{tabular}

Table 2. Analytical results of the main volatile compounds from the two different parts of Elsholtzia ciliata.

\begin{tabular}{|c|c|c|c|c|c|}
\hline \multirow[b]{2}{*}{ No } & \multirow[b]{2}{*}{$\begin{array}{l}\mathrm{RT} / \\
\mathrm{min}\end{array}$} & \multirow[b]{2}{*}{ Compound } & \multirow[b]{2}{*}{ Formula } & \multicolumn{2}{|c|}{ Relative Content/\% } \\
\hline & & & & $\begin{array}{c}\text { Stem } \\
\text { (with leaf) }\end{array}$ & Flower \\
\hline 1 & 15.38 & 3-Octen-1-ol & $\mathrm{C}_{8} \mathrm{H}_{16} \mathrm{O}$ & $0.61 \%$ & $0.69 \%$ \\
\hline 2 & 16.03 & $\beta$-Myrcene & $\mathrm{C}_{10} \mathrm{H}_{16}$ & $0.07 \%$ & $0.24 \%$ \\
\hline 3 & 16.47 & 3-Octanol & $\mathrm{C}_{8} \mathrm{H}_{18} \mathrm{O}$ & $3.11 \%$ & $1.53 \%$ \\
\hline 4 & 20.85 & Acetophenone & $\mathrm{C}_{8} \mathrm{H}_{8} \mathrm{O}$ & $0.15 \%$ & $0.26 \%$ \\
\hline 5 & 23.28 & Thymol & $\mathrm{C}_{10} \mathrm{H}_{14} \mathrm{O}$ & $0.17 \%$ & $0.58 \%$ \\
\hline 6 & 31.37 & Elsholtzia ketone & $\mathrm{C}_{10} \mathrm{H}_{14} \mathrm{O}_{2}$ & $84.20 \%$ & $88.03 \%$ \\
\hline 7 & 37.97 & $\begin{array}{c}\text { Dehydroelsholtzia } \\
\text { ketone }\end{array}$ & $\mathrm{C}_{10} \mathrm{H}_{12} \mathrm{O}_{2}$ & $0.41 \%$ & $1.23 \%$ \\
\hline 8 & 43.48 & Geranyl acetate & $\mathrm{C}_{12} \mathrm{H}_{20} \mathrm{O}_{2}$ & $0.15 \%$ & $0.06 \%$ \\
\hline 9 & 44.57 & $\beta$-Bourbonene & $\mathrm{C}_{15} \mathrm{H}_{24}$ & $0.45 \%$ & $0.08 \%$ \\
\hline 10 & 47.82 & Caryophyllene & $\mathrm{C}_{15} \mathrm{H}_{24}$ & $4.30 \%$ & $3.33 \%$ \\
\hline 11 & 49.63 & $\alpha$-Bergamotene & $\mathrm{C}_{15} \mathrm{H}_{24}$ & $0.12 \%$ & $0.17 \%$ \\
\hline 12 & 50.88 & Humulene & $\mathrm{C}_{15} \mathrm{H}_{24}$ & $0.37 \%$ & $0.24 \%$ \\
\hline 13 & 57.26 & Nerolidol & $\mathrm{C}_{15} \mathrm{H}_{26} \mathrm{O}$ & $0.10 \%$ & $0.12 \%$ \\
\hline
\end{tabular}


<smiles>Cc1ccc(C(C)C)c(O)c1</smiles>

Thymol

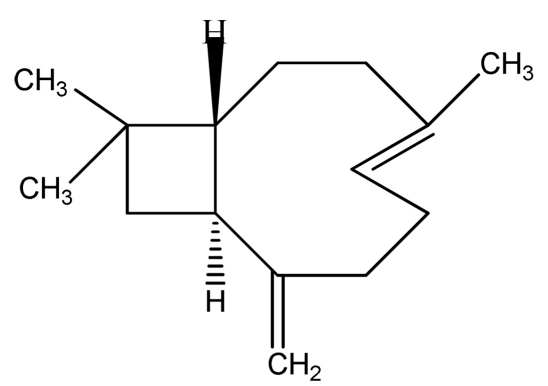

Caryophyllene<smiles>C=CC(C)(O)CCC=C(C)C</smiles>

Linalool<smiles>Cc1ccoc1C(=O)CC(C)C</smiles>

Elsholtzia ketone

Figure 3. Typical constituents, elsholtziaketone, caryophyllene, thymol and linalool.

were similar in the two parts of Elsholtzia ciliata, while the flower contained a slightly higher content of volatile components than the stem and leaf. 39 compounds were acquired in two different parts, including Elsholtzia ketone, Caryophyllene, 3-Octanol, Dehydroelsholtzia ketone, 1-Octen-3-ol, Thymol, $\beta$-Bourbonene, Acetophenoneand so on. Elsholtzia ketone, which is regarded as a typical compound to identify Elsholtzia ciliata, showed the highest content in both parts (88.03\% in the flower and $84.20 \%$ in the stem with leaf).

Seen from Table 2 , the main volatile components of more than $0.1 \%$ were almost same in both parts. In terms of the content, Caryophyllene accounted for a secondary content, $4.3 \%$ and $3.33 \%$ in the total quantity of volatile components (with certain difference in contents), respectively. The other components with a content of more than $0.1 \%$ were common among these two parts, varying in their contents in certain degrees. It could be concluded that, the main compositions of the volatile components in two parts were similar and shared a large number of components, only different in their contents. Thus we could further infer that both parts of Elsholtzia ciliata may have similar pharmacologic actions.

The present study shows only the comparison result between two different parts of the aerial parts of Elsholtzia ciliata collected at the same harvesting period and region while further work is needed to determine whether the comparison result of both parts at different harvesting periods is consistent with that obtained at the same harvesting period and region.

On the one hand, both parts share many components and their main components are similar, accounting for a large proportion; however, there are also difference in some compositions and contents. Such a difference is possibly related 
with the synthetic position and distribution of chemical components inside the plant. On the other hand, the differential peaks account for a small but significant proportion, attention should be paid to the existence of the differential peaks and the content control of various main components in selection of medicinal parts.

\section{Conclusions}

The HS-GS-MS technique is a rapid and efficient technique for the analysis of volatiles in samples with many advantages. In this project, it was successfully applied to the rapid analysis and comparison of the volatiles of the two different parts from Elsholtzia ciliata harvesting at the same time and region. For this method, the sample amount taken was only $0.5 \mathrm{~g}$ and operated in a highly automated way. The volatiles obtained by the method, when compared with hydrodistillation reported in some literatures, are that HS-GS-MS technique is more suitable for the analysis of the low boiling compounds.

In our experiments, a large amount of common constituent was detected in the two different parts of Elsholtzia ciliata. For the majority of compounds, the main constituent obtained in these two different parts was both the Elsholtzia ketone, accounting for more than $80 \%$ in the total volatiles. Other previous reports have studied that Elsholtzia ketone was the main bioactive components of Elsholtzia ciliata. Our results have shown that these two different parts both have a certain medicinal value in a degree. Therefore, it's significant to select the $E I-$ sholtzia ciliata aerial parts in the clinical application.

There is a difference observed between the contents of the volatile components of the two different parts. Although the differences were small and not obvious, it can still provide basis for comparison of the two different parts. Eventually, these findings provide a reference for further exploitation of Elsholtzia ciliata. The experimental results suggest that the proposed method in analysis of volatile compounds of Elsholtzia, has less sample consumption, no organic solvent extraction, and highly automatic analysis process. It can be applied for the fast analysis and distinguishing of the volatile compounds in Elsholtzia ciliata stems (with leafs) and flowers.

\section{References}

[1] Guo, Z., Liu, Z., Wang, X., et al. (2012) Elsholtzia: Photochemistry and Biological Activities. Chemistry Central Journal, 6, 147-148. https://doi.org/10.1186/1752-153X-6-147

[2] Ding, C.X. and Ji, L.J. (2005) Research Advance of the Chemical Component and Pharmacological Action of Elsholtzia. Shanghai Journal of Traditional Chinese Medicine, 39, 63-64.

[3] Li, J.E., Nie, S.P., Qiu, Z.H., et al. (2010) Antimicrobial and Antioxidant Activities of the Essential Oil from Herba Moslae. Science of Food and Agriculture, 90, 1347-1352. https://doi.org/10.1002/jsfa.3941

[4] Liu, A.L., Liu, B., Qin, H.L., et al. (2008) Anti-Influenza Virus Activities of Flavo- 
noids from the Medicinal Plant Elsholtzia rugulosa. Planta Medica, 74, 847-851. https://doi.org/10.1055/s-2008-1074558

[5] Tong, Y., Wang, J.Y., Ji, L., et al. (2006) Effect of Different Extraction Methods on the Essential Oils Quality of Mosla chinensis. Chinese Journal of Experimental Traditional Medical Formulae, 12, 24-25.

[6] Jiang, H.M., Lu, X.Y., Fang, J., et al. (2007) Study on Extraction Technology of Mosla chinensis Volatile Oil. Journal of Chinese Medicinal Materials, 30, 1135-1139.

[7] Rong, R., Qiu, L.L., Liu, P., et al. (2010) Gas Chromatography-Mass Spectrometry Analysis for Volatile Compounds in Rhizome zingiberis by Steam Distillation or Headspace Injection. Li Shi Zhen Medicine and Materia Medica Research, 21, 2810-2811.

[8] Deng, J.G. and Hou, X.T. (2012) Study of Non-Medicinal Parts of Traditional Chinese Medicine. Journal of Guangxi University of Chinese Medicine, 15, 68-71.

[9] Liu, X., Jai, J. and Yang, L. (2012) Evaluation of Antioxidant Activities of Aqueous Extracts and Fractionation of Different Parts of Elsholtzia ciliata. Molecules, 17, 5431-5438.

[10] Mathela, C.S., Melkani, A.B., Bisht, J.C., et al. (1992) Chemical Varieties of Essential Oils from Elsholtzia polystachya from Two Different Locations in India. Planta Medica, 58, 377-378. https://doi.org/10.1055/s-2006-961490

[11] Mathela, C.S., Padalia, R.C., Joshi, S.C., et al. (2009) Chemical Diversity in Himalayan Elsholtzia Species. Chemistry \& Biodiversity, 6, 2218-2224. https://doi.org/10.1002/cbdv.200800329

[12] Kobold, U., Vostrowsky, O., Bestmann, H.J., et al. (1987) Terpenoids from Elsholtzia Species; II. Constituents of Essential Oil from a New Chemotype of Elsholtziacristata. Planta Medica, 53, 268-271. https://doi.org/10.1055/s-2006-962701

[13] Bisht, J.C., Pant, A.K., Mathela, C.S., et al. (1985) Constituents of Essential Oil of Elsholtziastrobilifera. Planta Medica, 51, 412-413. https://doi.org/10.1055/s-2007-969535

[14] Bestmann, H.J., Rauscher, J., Vostrowsky, O., et al. (1997) The Volatile Constituents of Elsholtziaflava. Planta Medica, 63, 88-90. https://doi.org/10.1055/s-2006-957615

[15] Peng, H.Y. and Yang, X.E. (2005) Volatile Constituents in the Flowers of Elsholtziaargyi and Their Variation: A Possible Utilization of Plant Resources after Phytoremediation. Journal of Zhejiang University Science, 6, 92-94.

[16] Zhu, G.P. (1992) Comparison of Chemical Constituents of Essential Oils from Elsholtzia splendens and Cultivated Moslachinensis by GC-MS Analysis. Acta Pharmaceutica Sinica, 27, 287-292.

[17] Zhu, G.P. (1990) GC-MS Analysis of Essential Oil of 10 Species of Chinese Elsholtzia. China Journal of Chinese Materia Medica, 15, 678-679.

[18] Li, J., Liu, H.Y. and Zhang, Y.Q. (2013) Analysis of Volatile Chemical Constituents from Two Species of Elsholtzia Herb by HS-SPME-GC-MS. Chinese Journal of EXperimental Traditional Medical Formulae, 19, 118-122.

[19] Saini, R., Guleria, S., Kaul, V.K., et al. (2010) Comparison of the Volatile Constituents of Elsholtziafruiticosa Extracted by Hydrodistillation, Supercritical Fluid Extraction and Head Space Analysis. Natural Product Communications, 5, 641-643. 